\title{
Effects of power electronics devices on the energy quality of an administrative building
}

\author{
Jorge I. Silva ${ }^{1}$, Vladimir Sousa ${ }^{2}$, Paulo Sarmiento ${ }^{3}$, Julio R. Gómez ${ }^{4}$, Percy R. Viego ${ }^{5}$, \\ Enrique C. Quispe6. \\ 1, 2,3 Energy Department, Universidad de la Costa, Colombia \\ ${ }^{4,5}$ Center of Energy and Environmental Studies, Universidad de Cienfuegos, Cuba \\ ${ }^{6}$ Energy and Mechanical Department, Universidad Autónoma de Occidente, Colombia
}

\begin{abstract}
Article Info
\section{Article history:}

Received Mar 4, 2019

Revised Jun 6, 2019

Accepted Jul 8, 2019

\section{Keywords:}

Administrative building

Effects of harmonics

Non-linear loads

Power electronics devices

Energy quality

ABSTRACT

This paper proposes the analysis of the effects of power electronics devices on the energy quality of an administrative building. For the study a method is applied that allows the analysis of the main problems of energy quality such as voltage variation, harmonics, flicker, and the effect of harmonics on the power factor. As a case study, the offices of an administrative building were used, where the measurements of the main energy quality parameters were carried out for a week. The results showed the presence of current harmonics and flicker problems due to non-linear loads such as the frequency inverters that drive the motors of the elevators and escalators, as well as the LED lamps. These problems cause systematic damage to the lighting system, UPS and improper correction of the power factor. The study also demonstrates the need to deepen the effects of energy quality not only in the industrial and residential sectors. In addition, attention must be paid to the tertiary sector, specifically to administrative buildings.
\end{abstract}

Copyright (C) 2019 Institute of Advanced Engineering and Science. All rights reserved.

\section{Corresponding Author:}

Vladimir Sousa,

Energy Department,

Universidad de la Costa,

Calle 58 No.55-66, Barranquilla, Colombia.

Email: vsousa1@cuc.edu.co

\section{INTRODUCTION}

Currently, the efficient use of energy is closely linked to cleaner production and sustainable development [1]. Among consumers of energy globally, electricity represents $18.8 \%$ of fuel consumption [2] and produces $42 \%$ of $\mathrm{CO} 2$ emissions [3], with a projection of continuous growth in demand [4]. For this reason, special attention should be paid to its efficient use.

In recent times, new forms of production and consumption of electricity have been developed, with an increase in the use of electronic devices that have increased the problems of energy quality [5-7]. Among these equipment are static power converters, discharging devices in the form of electric arcs, saturated magnetic devices and uninterruptible power systems (UPS) [8-10]. There are several studies where the negative effects of these equipment on the functioning of the electrical system and its components are analyzed, such as the reduction of the useful life and the increase of the energy losses.

In [11] the increase in the harmonics that occurs in an industrial electrical system where PWM inverters predominate is evaluated, and it is demonstrated how the harmonics reach high values that affect the operation of motors, transformers and capacitors. The reduction in the useful life of the induction motors due to the overheating produced by the harmonics generated by the electronic devices is studied in [12-14]. In [15] the increase in copper losses of the motors produced by the PWM inverters is analyzed, while in $[16,17]$, the discharge of current in the bearings caused by these devices is evaluated. 
The negative effects due to the combination of the harmonics and the voltage imbalance in the operation of the motors are analyzed in [18]. In [19] emphasis is placed on the increase in the oscillation of the torque ripple and in the vibrations produced by both phenomena.

The studies developed in $[20,21]$, focus on the increasing affectation that occurs in the transformers as a result of the increase of the non-linear loads that they feed. In [20, 22] it is analyzed the overheating in the iron and the reduction in the useful life of a transformer that feeds a residential circuit with predominance of electronic loads.

One of the main components of the electrical system that is being harmed the most with the increase of electronic devices are the capacitors. In [23] the increase of the temperature, the noise and the affectation in the dielectric elements of the capacitors produced by the harmonics are studied. The resonance effect is studied in [24] and it is demonstrated how the useful life of these elements can be significantly reduced by operating in an electrical system with distorted waves.

The studies on energy quality mentioned, and others such as those reported in [25-28] focus on the electric power system, industrial and residential sector, however, in no case the quality of energy in administrative buildings is analyzed. Therefore, this paper analyzes a new performance evaluation of the energy quality in administrative buildings.

Buildings are an important objective in energy efficiency studies since they consume $40 \%$ of total energy and emit $30 \%$ of global greenhouse gases [29-31]. Administrative or office buildings, due to their constructive characteristics and their use, have a high incidence in the referred consumption [32, 33]. This consumption is mainly due to the intensive use of air conditioning systems [34, 35].

In the city of Barranquilla, Colombia, where the study is carried out, the field of construction maintains a positive dynamic, which is reflected in the growth that the city has had in recent years. This growth produces an increase in the consumption of electrical energy, due to the need to satisfy building requirements and user comfort [36].

The use of non-linear loads with significant energy consumption such as frequency inverters for the drive of elevator motors [37], air conditioning systems with inverter technology [38], LED lamps [39] and UPS [40], among others have also increased in buildings. Due to these aspects, this work is important becauses aims to evaluate the behavior of the quality of energy in an administrative building.

The paper is structured as following. The characteristics of the energy quality problems analyzed, and the method used for the study are described in section 2 . Section 3 presents and analyzes the results obtained in a case study in the offices of an administrative building with loads non-linear, while the study conclusions are presented in section 4.

\section{RESEARCH METHOD}

The circuits that feed the administrative areas can be affected by the problems of energy quality that are commonly presented in electrical distribution systems such as voltage variation, flickers, harmonic distortion and displacement power factor $[11,18,41]$. The main characteristics of these phenomena that were evaluated in the study are described below.

\subsection{Voltage variations}

The voltage variation is the changes in the magnitude (amplitude) of the steady-state voltage when the system operates at nominal frequency $(60 \mathrm{~Hz})$ [41]. A low voltage circuit has voltage variation problems if the effective value is outside the range of $\pm 10 \%$ in relation to the nominal value for a time greater than one minute [41].

\subsection{Flickers}

This phenomenon is defined from the perception of flicker in electric lights, caused by changes in the effective value of the voltage. The parameters used for the evaluation of flicker are the short-term perception (Pst), obtained by periodic measurements every ten minutes and the long-term perception (Plt), obtained by periodic measurements of two hours [41, 42]. The Plt is obtained from Pst, according to (1) [42].

$$
\text { Plt }=\sqrt[3]{\frac{1}{12} \times \sum_{j=1}^{12} \text { Pst }_{j}^{3}}
$$

Under steady-state operating conditions, Pst and Plt must comply with the limits shown in Table 1 for a voltage below $69 \mathrm{kV}[42]$.

Int J Pow Elec \& Dri Syst Vol. 10, No. 4, Dec 2019 : 1951 - 1960 
Table 1. Compatibility levels for Pst and Plt in power systems of voltage below $69 \mathrm{kV}$

\begin{tabular}{cc}
\hline \multicolumn{2}{c}{ Compatibility levels } \\
\hline Pst & 1.0 \\
Plt & 0.8 \\
\hline
\end{tabular}

\subsection{Harmonic distortion}

A harmonic is a component of the harmonic distortion in the waveform of voltage and current produced primarily by non-linear devices. Harmonics are defined as a sinusoidal component of a frequency that is an integral multiple of the fundamental frequency of the electric network [43, 44]. A distorted wave of voltage or current is the result of the sum of harmonics.

The fundamental parameters for the harmonic characterization are: total harmonic distortion of voltaje (THDv) and current (THDi), the total demand distortion (TDD) individual voltage distortion (IDv) and individual current distortion (IDi). These parameters are calculated with (2), Reference source not found., (5) and (6) [43, 44].

(3), Error!

$$
\begin{aligned}
& \text { THDv }=\frac{\sqrt[2]{\sum_{\mathrm{h}=2}^{40} \mathrm{~V}^{2} \mathrm{~h}}}{\mathrm{~V}_{1}} \\
& \text { THDi }=\frac{\sqrt[2]{\sum_{\mathrm{h}=2}^{\infty} \mathrm{I}^{2} \mathrm{~h}}}{\mathrm{I}_{1}} \\
& \mathrm{TDD}=\frac{\sqrt[2]{\sum_{\mathrm{h}=2}^{\infty} \mathrm{I}^{2} \mathrm{~h}}}{\mathrm{I}_{\mathrm{L}}} \\
& \mathrm{IDV}=\frac{\mathrm{V}_{\mathrm{h}}}{\mathrm{V}_{1}} \\
& \mathrm{IDi}=\frac{\mathrm{I}_{\mathrm{h}}}{\mathrm{I}_{1}}
\end{aligned}
$$

where $\mathrm{h}$ is the order of the higher harmonics and $\mathrm{I}_{\mathrm{L}}$ is the maximum load current or peak demand.

According to the IEEE Standard Std 1159-2014 [44] for voltage lower than $1 \mathrm{kV}$ and the ratio between the short-circuit current (Isc) and maximum demand $\left(\mathrm{I}_{\mathrm{L}}\right)$ in the range between 100 and 1000 , the THDv, IDv, TDD and THDi must not exceed the values presented in Table 2. For the evaluation of IDi, the limits values showed in Table 3 are considered for different harmonic intervals corresponding to the relationship between Isc and IL indicated [44].

Table 2. Limits of THDv, IDv and TDD [44]

\begin{tabular}{lllll}
\hline Parameters & THDv & ID & TDD & THDi \\
\hline Limits (\%) & $8 \%$ & $5 \%$ & $15 \%$ & $20 \%$ \\
\hline
\end{tabular}

Table 3. Current distortion limits for systems from

\begin{tabular}{llll}
\multicolumn{4}{c}{$120 \mathrm{~V}$ to $69 \mathrm{kV}[44]$} \\
\begin{tabular}{llll}
\hline Individual order of harmonics \\
\hline Isc/Il & $3 \leq \mathrm{h}<11$ & $11 \leq \mathrm{h}<17$ & $17 \leq \mathrm{h}<23$ \\
\hline $100<1000$ & 12.0 & 5.5 & 5.0 \\
\hline
\end{tabular}
\end{tabular}

\subsection{Displacement power factor}

The power factor is a parameter that relates the active power $(\mathrm{P})$ and the apparent power $(\mathrm{S})$. The component of the displacement of the power factor (DPF) is the relation between the indicated powers of the fundamental component wave. the (7) shows the corresponding equation based on the power triangle [10].

$$
\mathrm{DPF}=\frac{\mathrm{P}}{\mathrm{S}}=\cos \theta
$$

The parameter $\mathrm{S}$ for the fundamental component of the voltage and current wave is determined as:

$$
\mathrm{S}=\sqrt{\mathrm{P}^{2}+\mathrm{Q}^{2}}
$$

For systems with distorted waves where harmonics are added to the fundamental wave, the power triangle is modified and the apparent power is calculated according to (9) [43].

$$
\mathrm{S}=\sqrt{\mathrm{P}^{2}+\mathrm{Q}^{2}+\mathrm{D}^{2}}
$$


Under these conditions, the power factor is defined as a True Power Factor (TPF). Its definition represented in (10) is obtained by replacing (9) in (7) that allows analyzing the influence of harmonics on the power factor.

$$
\mathrm{TPF}=\frac{\mathrm{P}}{\sqrt{\mathrm{P}^{2}+\mathrm{Q}^{2}+\mathrm{D}^{2}}}
$$

\subsection{Steps of method}

In the present study, the following steps were established to study the quality of energy:

a. Measurement in the main board with a power analyzer of the electrical parameters of voltage, Plt, harmonics and displacement and true power factor.

b. Evaluation of the voltage graph obtained in the measurements. Analyze if the maximum voltage values are within $\pm 10 \%$ of the nominal voltage of the transformer.

c. Analysis of the Plt graph obtained in the measurements. Evaluate if the measured values are below 0.8 within the $95 \%$ percentile.

d. Analysis of harmonic distortion considering the following parameters:

- Evaluation of the THDv graph obtained in the measurements and verify that the values are below $8 \%$.

- $\quad$ Evaluation of the THDi graph and verify that the values are below $20 \%$.

- Evaluation of the individual harmonics and TDD and compare the values with the limits of 15\% presented in Table 3.

e. Evaluation of the DPF and TPF measured and compare the values in relation to 0.9 which is the limit established by the energy supply companies. It is also determined the incidence of the harmonics on the power factor.

\section{RESULTS AND DISCUSSION}

The study of energy quality was carried out in the offices of a company that occupy two floors of a ten-story business complex in Barranquilla city, Colombia. The company offices have 20 workstations with computers, 20 panel luminaires with 50W LED lamps and a 5-ton central air conditioner. The supply circuit of these offices is influenced by the network of the building that presents several non-linear loads such as frequency variators and LED lamps, belonging to the common area of the complex and to the escalators and elevators. These loads cause distortions in the waveform and disturbances in the electrical system, which can be the cause of the damage to the luminaires of the offices and the shots to the protections of the UPS that occurs systematically.

The measurements were made with a power analyzer Metrel model MI2892. The measurements were carried out for seven days with data recording period every ten minutes. The instrument was placed in the main switch of the distribution board. In Figure 1 the one-line diagram with the connection point of the power analyzer is shown. Next, the evaluation results of the measured parameters are analyzed.

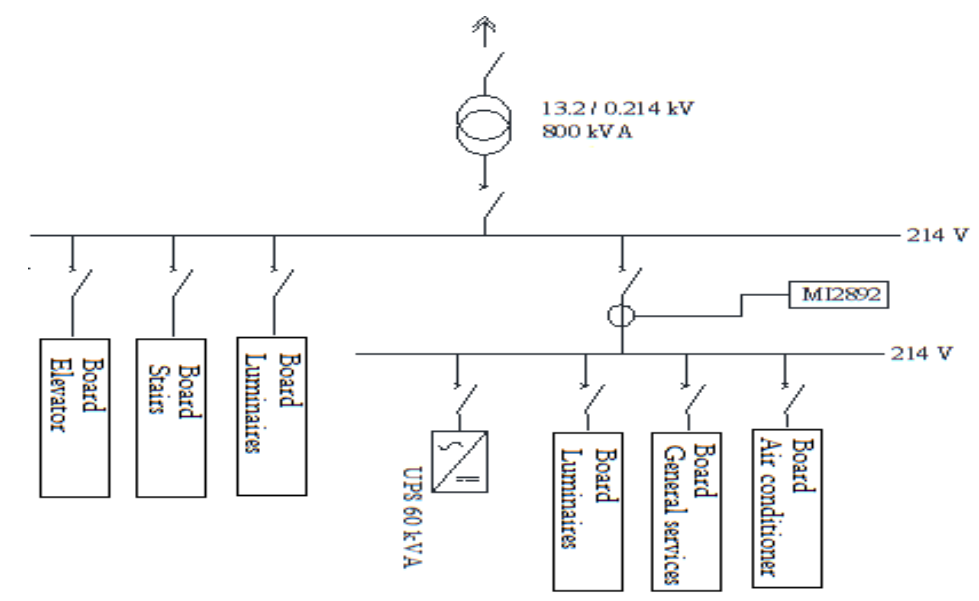

Figure 1. One-line diagram 


\subsection{Analysis of voltage variation}

In Figure 2 the voltages measured in the three lines (U12, U23 and U31) are shown. The average of the voltages was of $218.63 \mathrm{~V}$, while the maximum and minimum values were of $229.49 \mathrm{~V}$ and $210.81 \mathrm{~V}$ respectively. Considering that the nominal voltage in the network analyzed is $214 \mathrm{~V}$, it can be concluded that the average voltage is $2.16 \%$ greater than the nominal voltage, the maximum voltage is $7.24 \%$ higher and the minimum is $1.49 \%$ lower, therefore, they are within the established limit of $\pm 10 \%$.

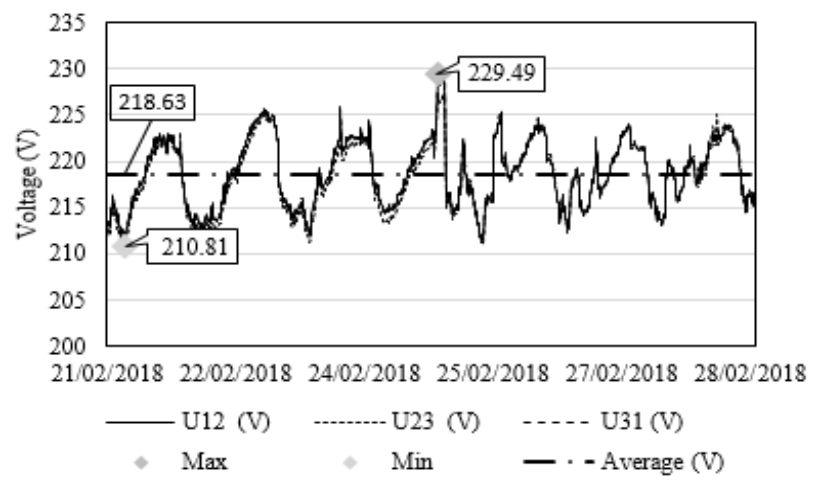

Figure 2. Measured voltage

\subsection{Analysis of flicker}

In Figure 3 (a) the Plt of the three lines is shown. As can be seen, most of the values are below 0.8 which is the limit established in Table 1, while some values do exceed this value. In Figure 3 (b) it can also be observed, by means of a percentile graph that the values below the limit comprise $86.7 \%$ of the data. This result implies a problem of energy quality due to the presence of flicker, since it is expected that the values must be less than 1 in $95 \%$ of the data at least.

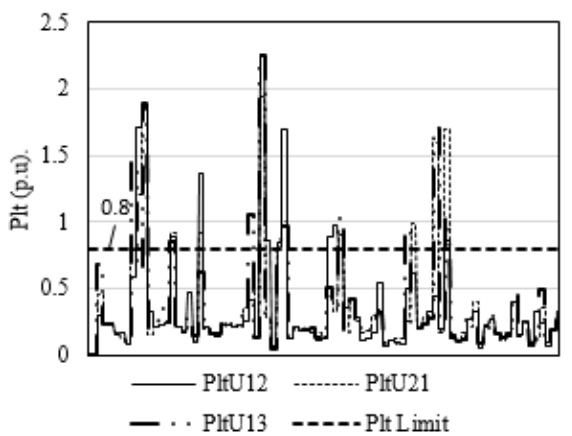

(a)

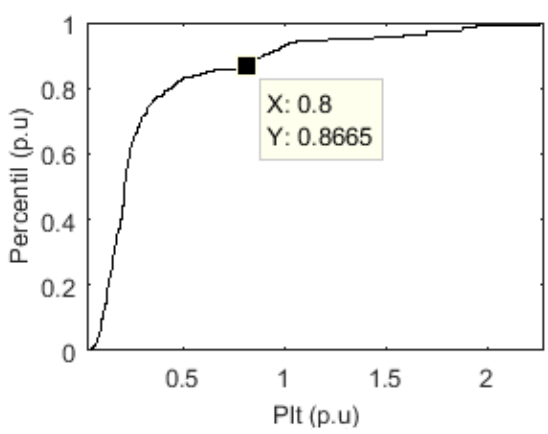

(b)

Figure 3. Measurement of Plt, (a) graphic of Plt, (b) percentile graph for Plt measurements

\subsection{Analysis of THDv and IDv}

In Figure 4 (a) the THDv measurements are shown, while in Figure 4 (b) the behavior of the individual voltage harmonics can be observed. In these graphs, voltage harmonic problems are not evidenced since the measured values are lower than $8 \%$ and $5 \%$ respectively, limits established by the standards and shown in Table 2. For the THDv, the maximum value was $5.69 \%$ while in the individual harmonics it was $1.75 \%$. 


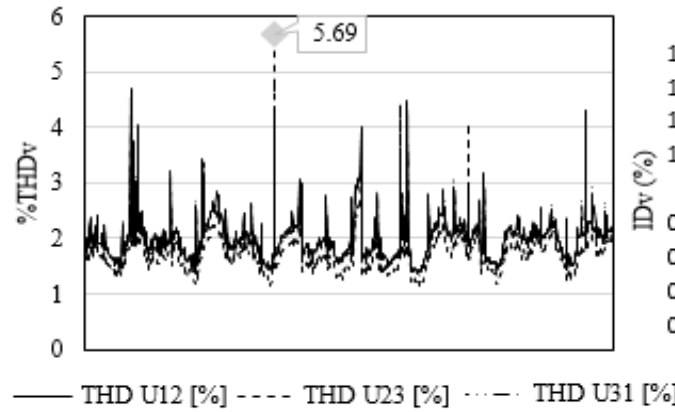

(a)

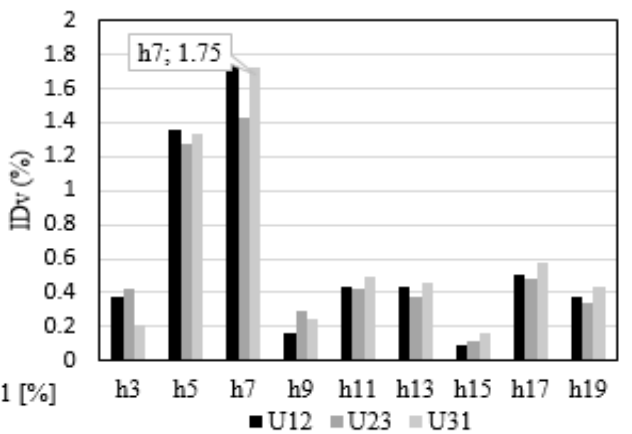

(b)

Figure 4. Measurement of THDv, (a) graphic of THDv, (b) bar graphs of individual voltage harmonics

\subsection{Analysis of THDi}

Figure 5 (a) represents the measured THDi values. In this case, most of the data are above $20 \%$, the limit value established by the standards and presented in Table 1. In Figure 5 (b) it is observed in the percentile graph, that $76.3 \%$ of the data exceed the limit, therefore, a problem of harmonics in the current caused by non-linear loads is evident.

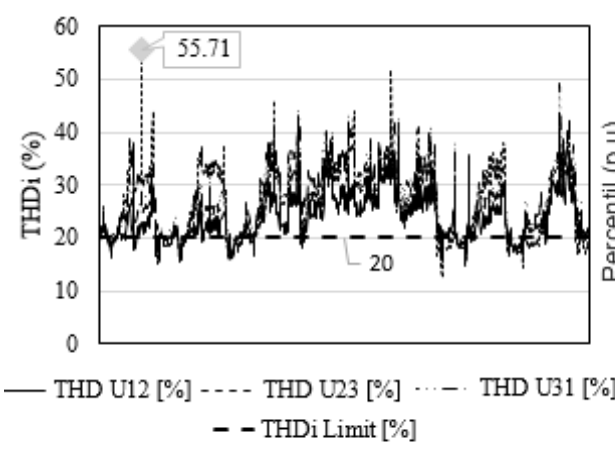

(a)

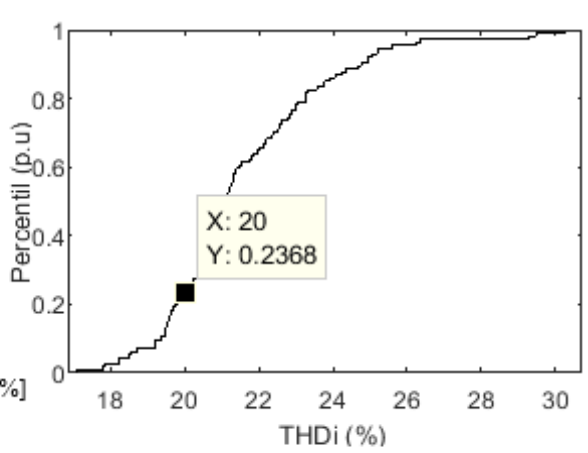

(b)

Figure 5. Measurement of THDi, (a) graphic of THDi, (b) percentile graph for THDi measurements

\subsection{Analysis of TDD and IDi}

The measured TDD values are shown in Figure 6 (a). According to the IEEE Std 519-2014 [44] these values must be less than $15 \%$, because the Isc/ $\mathrm{I}_{\mathrm{L}}$ ratio is between $100<1000$. In Figure 6 (b) the percentile graph is represented. As noted, $18 \%$ of the samples during the measurement period are above the percentage recommended by the standard. This behavior represents a problem of energy quality due to harmonics of current since the standard establishes that the values must be lower than the limit in $95 \%$ of the registered samples.

The values of individual harmonics by a bar graph are presented in Figure 7. Comparing these values with the limits of Table 3, is showed that harmonics of 5th and 7th order with IDi values of $12.99 \%$ and $31.62 \%$ respectively, are above the limit of $12 \%$ indicated for the harmonics between 3rd and 10 th level. In addition, the harmonic of order 11 with an IDi of $7 \%$ is above the limit of $5.5 \%$ established for the harmonics between 11 th and 17 th levels. 


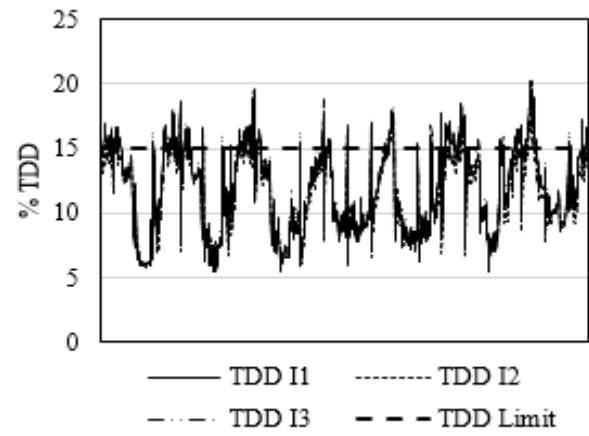

(a)

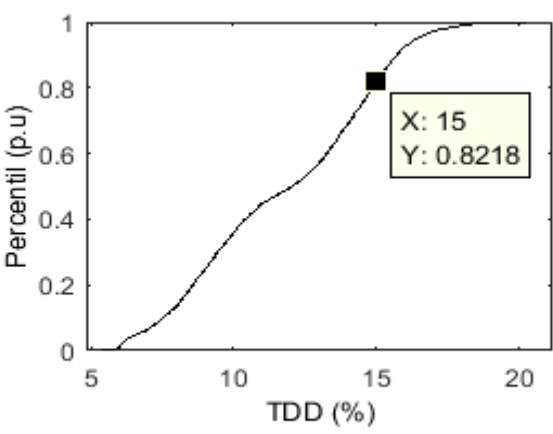

(b)

Figure 6. Measurement of TDD, (a) graphic of TDD, (b) percentile graph for TDD measurements

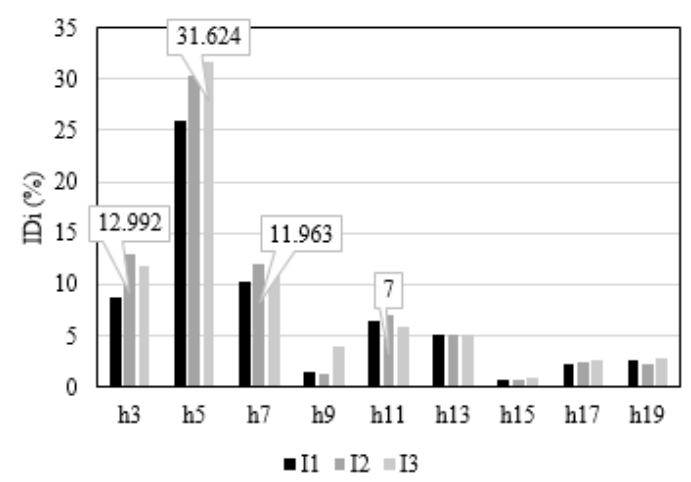

Figure 7. IDi bar graph

\subsection{Analysis of power factor}

The DPF and TPF are shown in Figure 8 (a) and (b) respectively. As can be seen, the two parameters are above 0.9 in most of the records thus fulfilling the requirements of the energy distribution company. The results also show that the TPF values of Figure 8 (b) are smaller than the DPF of Figure 9 (a), even with a record of 0.853 due to the effect of the harmonics. The zero values are due to interruptions in the power supply.

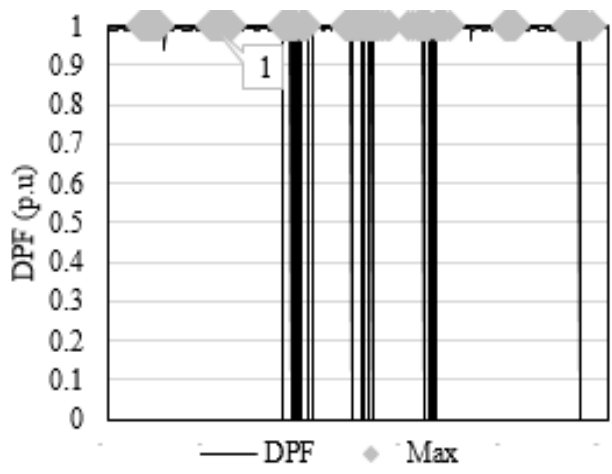

(a)

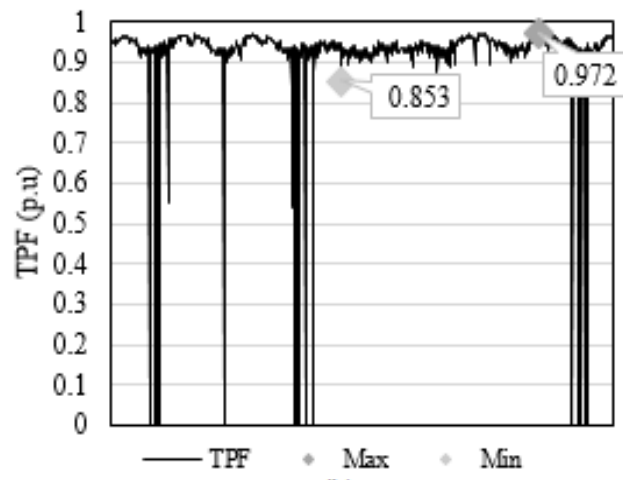

(b)

Figure 8. Measurement of power factor, (a) graphic of DPF, (b) graphic of TPF 


\subsection{Causes and effects of the disturbances identified}

The results obtained show that the variable speed drives of the induction motors of the elevator and the escalators systems provoke the individual harmonics of the 5th and 7th order, which are the most generated by three-phase rectifiers $[11,45]$. In addition, it was possible to demonstrate the production of harmonics by the LED lamps.

These identified problems could partially explain the problems that are systematically presented in the electronic boards of the lighting system due to the individual harmonics of zero sequence, and the problems presented by flickers in the luminaires. Finally, the power factor is affected by the presence of the harmonics, decreasing the real value. This produces false readings in the control equipment for reactive compensation, and therefore detracts injecting the reactive power needed for compensating the power factor of the system.

\section{CONCLUSION}

The present study demonstrates the need to focus the analysis of the effects of poor quality of energy not only in the electric power system, industrial and residential sector but also in the tertiary sector as in administrative buildings.

The results of the case study presented in an administrative building showed the affectation of the energy quality caused by the frequency inverters of elevator and escalators motors, as well as LED lamps. This was reflected in the parameters of the THDi, IDi, TDD and flicker, with values that exceeded the limits established by the standards.

It was possible to verify how the identified phenomena could be the causes of problems present in the installation of the building in the lighting systems, in the UPS and in the inadequate correction of the power factor. Due to this, the installation of passive filters is recommended to reduce the identified harmonics.

\section{REFERENCES}

[1] L. Hens, et al., "On the evolution of "Cleaner Production" as a concept and a practice," Journal of cleaner production, vol. 172, pp. 3323-3333, 2018.

[2] IEA, "Key world energy statistics," International energy agency, Paris, 2018.

[3] IEA, " $\mathrm{CO}_{2}$ Emissions from Fuel Combustion 2018," International energy agency, Paris, 2018.

[4] J. W. Grimaldo, et al., "Forecast electricity demand model using predicted values of sectorial gross domestic product: Case of Colombia," Espacios, vol. 38, pp. 3-14, 2017.

[5] S. Rönnberg and M. Bollen, "Power quality issues in the electric power system of the future," The electricity journal, vol. 29, pp. 49-61, 2016.

[6] R. Aboelsaud, et al., "Review of three-phase inverters control for unbalanced load compensation," International journal of power electronics and drive system (IJPEDS), vol. 10, pp. 242-255, 2019.

[7] S. A. Zegnoun, et al., "Power quality enhancement by using D-FACTS systems applied to distributed generation," International journal of power electronics and drive system (IJPEDS), vol. 10, pp. 330-341, 2019.

[8] A. Rash, et al., "Harmonics-what are they, how to measure them and how to solve the problem (in connection with standards IEEE 1159-1995 and IEEE 519-1992)," in Proceedings of 19th convention of electrical and electronics engineers in Israel, 1996, pp. 83-86.

[9] J. Mazumdar and R. G. Harley, "Determining IEEE 519 compliance of a customer in a power system," in 2007 IEEE Power electronics specialists conference, 2007, pp. 2758-2764.

[10] IEEE, IEEE Std 519-1992: Recommended practices and requirements for harmonic control in power systems, 1993.

[11] V. Sousa, et al., "Harmonic distortion evaluation generated by pwm motor drives in electrical industrial systems," International journal of electrical and computer engineering (IJECE), vol. 7, pp. 3207-3216, 2017.

[12] S.R. Movahed, et al., "Estimation of insulation life of inverter- fed induction motors," in 2010 1st Power electronic \& drive systems \& technologies conference (PEDSTC), 2010, pp. 335 - 339.

[13] H. Oraee, "A quantative approach to estimate the life expectancy of motor insulation systems," IEEE Transactions on dielectrics and electrical insulation, vol. 7, pp. 790-796, 2000.

[14] A. Inan and F. Attar, "The life expectancy analysis for an electric motor due to harmonics," in Proceedings electrotechnical conference, MELECON 98, vol.2, 1998, pp. 997-999.

[15] G. K. Singh, "A research survey of induction motor operation with non-sinusoidal supply wave forms," Electric power systems research, vol. 75, pp. 200-213, 2005.

[16] Y. Wang, et al, "Calculation of high frequency bearing currents of PWM inverter-fed VF induction motor," in Proceedings 2014 International power electronics and application conference and exposition, Shanghai, 2014. pp. 1428-1433.

[17] Y. Wang, et al, "Research on discharging bearing currents of PWM inverter-fed variable frequency induction motor," in Proceedings electrical machines and systems (ICEMS), 2014, pp. 2945-2949. 
[18] V. Sousa, et al, "Estimating induction motor efficiency under no-controlled conditions in the presences of unbalanced and harmonics voltages," in 2015 CHILEAN Conference on electrical, electronics engineering, information and communication technologies (CHILECON), 2015, pp. 567-572.

[19] P. Donolo, et al., "Voltage unbalance and harmonic distortion effects on induction motor power, torque and vibrations," Electric power systems research, vol. 140, pp. 866-873, 2016.

[20] M. Digalovski, et al, "Impact of current high order harmonic to core losses of three-phase distribution transformer," in Proceedings. EUROCON, 2013, pp. 1531-1535.

[21] D. M. Said, et al, "Analysis of distribution transformer losses and life expectancy using measured harmonic data," in Proceedings 14th International conference on harmonics and quality of power - ICHQP 2010, 2010, pp. 1-6.

[22] M. T. Bishop, et al., "Evaluating harmonic-induced transformer heating," IEEE Transactions on Power Delivery, vol. 11, pp. 305-311, 1996.

[23] W. Chen and Z. Cheng, "An experimental study of the damaging effects of harmonics in power networks on the capacitor dielectrics," in Proceedings second international conference on properties and applications, vol.2, 1988. pp. 645-648.

[24] C. Boonseng, et al, "Failure analysis of dielectric of low voltage power capacitors due to related harmonic resonance effects," in Proceedings power engineering society winter meeting, vol.3, 2001, pp. 1003-1008.

[25] A. S. Gutiérrez, et al., "Electricity management in the production of lead-acid batteries: The industrial case of a production plant in Colombia," Journal of cleaner production, vol. 198, pp. 1443-1458, 2018.

[26] E. C. Quispe, et al., "Unbalanced voltages impacts on the energy performance of induction motors," International journal of electrical and computer engineering (IJECE), vol. 8, pp. 1412-1422, 2018.

[27] J. I. Silva-Ortega, et al., " Monitoring electromagnetic fields and safe operation levels in electrical power transmission lines," Chemical engineering transactions, vol. 67, pp. 715-720, 2018.

[28] J. I. Silva-Ortega, et al., "Demand energy forecasting using genetic algorithm to guarantee safety on electrical transportation system," Chemical engineering transactions, vol. 67, pp. 787-792, 2018.

[29] M. Liua and B. Mi, "Life cycle cost analysis of energy-efficient buildings subjected to earthquakes," Energy and buildings, vol. 154, pp. 581-589, 2017.

[30] M. Balbis, et al., "Energy assessment of the system pumping a climate control scheme with water coolers for an educational building using dynamic simulation," Espacios, vol. 38, pp. 19-31, 2017.

[31] M. Barros, et al., "Energy consumption comparison between air conditioning system mini-split and variable refrigerant flow in an educational building," Espacios, vol. 38, pp. 19-27, 2017.

[32] Z. Zheng, et al., "Study on energy consumption ration for office buildings," Energy procedia, vol. 142, pp. 2317-2322, 2017.

[33] J. Jia and W. Lee, "The rising energy efficiency of office buildings in Hong Kong," Energy and buildings, vol. 166, pp. 296-304, 2018

[34] J. J. C. Eras, et al., "Tools to improve forecasting and control of the electricity consumption in hotels," Journal of cleaner production, vol. 137, pp. 803-812, 2016.

[35] J. A. Madrigal, et al., "Evaluation of air conditioning in commercial buildings, integrating thermography techniques, simulation and modeling by finite elements," Información tecnológica, vol. 29, pp. 179-188, 2018.

[36] A. Ospino, et al., "Analysis of energy management and financial planning in the implementation of photovoltaic systems," International journal of energy economics and policy, vol. 9, pp. 1-11, 2019.

[37] A. De Almeida, et al., "Energy-efficient elevators and escalators in Europe: An analysis of energy efficiency potentials and policy measures," Energy and buildings, vol. 47, pp. 151-158, 2012.

[38] X. Xu, et al., "A review on temperature and humidity control methods focusing on air-conditioning equipment and control algorithms applied in small-to-medium-sized buildings," Energy and buildings, vol. 162, pp. 163-176, 2018.

[39] C. K. Gan, et al., "Techno-economic analysis of LED lighting: A case study in UTeM's faculty building," Procedia Engineering, vol. 53, pp. 208-216, 2013.

[40] A. Moreno-Munoz, et al., "Distributed DC-UPS for energy smart buildings," Energy and buildings, vol. 43, pp. 93-100, 2011.

[41] IEEE, IEEE Std 1159: IEEE Recommended practice for monitoring electric power quality, 2009.

[42] IEEE, IEEE Std 1453-2004: IEEE Recommended practice for measurement and limits of voltage fluctuations and associated light flicker on ac power systems, 2005.

[43] H. W. Beaty, et al., "Electrical power systems quality", Chicago: McGraw Hill, 2004.

[44] IEEE, EEE 519-2014: Recommended practice and requirements for harmonic control in electric power systems., 2014.

[45] V. Sousa, et al., "Assessment of the energy efficiency estimation methods on induction motors considering realtime monitoring," Measurement, vol. 136, p. 237-247, 2019. 


\section{BIOGRAPHIES OF AUTHORS}
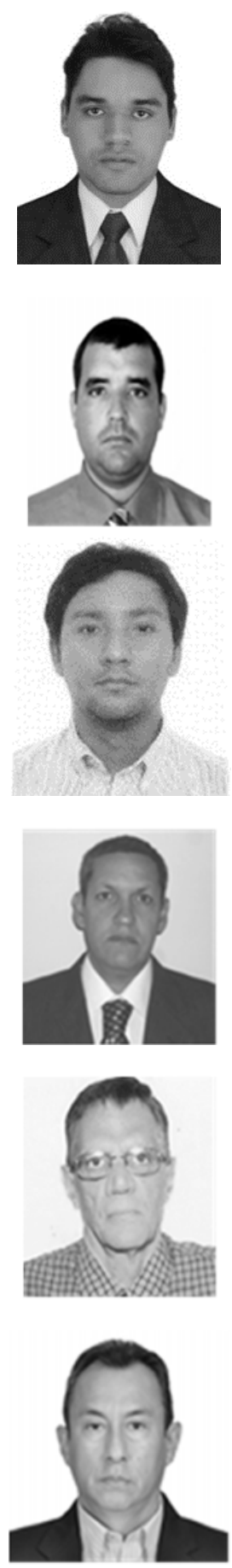

Jorge I. Silva was born in Barranquilla, Colombia on Octuber 30, 1988. Received the B.S degree in Electrical and electronic Engineering from Universidad del Norte, Colombia, in 2010. Received the M.Sc. degree in Electrical Engineering from Universidad del Norte, Colombia, in 2013. Currently is student at engineer Ph.d. Program at Universidad Pontificia Boliariana in Medellín Colombia. He is an active professor at the Energy Department of Universidad de la Costa (CUC), Colombia in works with GIOPEN group. His work experience is related to the electrical energy works sector. His research interests include: electrical power systems, electrical engineering education; planning, operation and control of power systems; and smart grids. https:/orcid.org/0000-0002-7813-0142

Vladimir Sousa was born in Cienfuegos, Cuba on November 21, 1980. Received the B.S degree in Electrical Engineering from Universidad Central de Las Villas, Cuba, in 2004. Received the M.Sc. degree in Energy Efficiency from Universidad de Cienfuegos, Cuba, in 2006. Received the Dr.C. (Ph.D.) degree from Universidad Central de Las Villas, Cuba, in 2014. Currently is with GIOPEN of Energy Department of Universidad de la Costa (CUC), Colombia. His area of interest includes electric machines, power quality and energy efficiency.

Paulo Sarmiento was born in Sabanalarga, Atlantico, on October 25, 1984. He received the B. Sc. In Electronic Engineering from the Universidad de la Costa, Colombia in 2013. He is specialist in project management at Universidad de la Costa, Colombia. He has experience in leadership of engineering department oriented to the planning, execution and control of projects of assembly of electrical systems, automation, industrial maintenance, intervention of projects, analysis and solutions of quality of electrical energy and commercial management for bidding of projects. Currently he develops a research internship at GIOPEN group.

Julio R. Gómez Sarduy was born in 1963 in Cienfuegos, Cuba. Received the B.S degree in electrical engineering from Universidad Central de Las Villas, Santa Clara, Cuba, in 1986. Received the M.Sc. degree in electrical engineering from Universidad Central de Las Villas, Santa Clara, Cuba, in 1996, from there he received his Ph.D. degree in 2006. Currently is with the Center for the Study of Energy and Environment (CEEMA). Faculty of Engineering, Universidad de Cienfuegos, Cienfuegos, Cuba. His area of interest includes electric machines, power quality and energy efficiency in industrial power systems.

Percy R. Viego Felipe was born in Cienfuegos, Cuba on November 19, 1944. Received the B.S. degree in Electrical Engineering from the Universidad Central de Las Villas, Santa Clara, Cuba, in 1965. Received the Dr.C. (Ph.D.) degree from the Central Universidad Participated in a postdoctoral scholarship on single-phase induction machine design at the Lappeenranta University of Technology, Finland, in 1994. Currently is with the Center of Energy and Environmental Studies (CEEMA), Faculty of Engineering, Universidad de Cienfuegos, Cuba.

Enrique C. Quispe (M'95. SM'12) was born in Lima, Perú, on January 20, 1956. He received the B.Sc. in Electrical Engineering from the Universidad Nacional de Ingeniería, Perú in 1980. M.Sc. in Electrical Engineering, M. Eng. in Industrial Automation and PhD. in Electrical Engineering from Universidad del Valle, Colombia in 1994, 1997 and 2011, respectively. Since 1992, he has been with Universidad Autónoma de Occidente, Cali, Colombia, where he is currently Full Professor in the Department of Energy and Mechanics and the Director of the Energy Research Group. His current research interests include the analysis of electrical machines and drives, power quality and management and energy efficiency. He is an IEEE Senior Member. 